\title{
Leitura crítica da mídia e narrativas audiovisuais: experiência de jovens no município mineiro de Mariana
}

\author{
Marta Regina Maia \\ marta@martamaia.pro.br \\ Universidade Federal de Ouro Preto | Brasil \\ Monique Ferreira Campus \\ moniquecampos@hotmail.com \\ Universidade Federal de Ouro Preto | Brasil
}

\section{Resumo}

As questões que envolvem a articulação entre mídia e educação perpassam o contexto contemporâneo, marcado pela forte presença das tecnologias de comunicação nos processos socioculturais. Há, portanto, a necessidade de promoção de leituras críticas da mídia. Nesse processo interativo, os questionamentos podem tensionar as práticas midiáticas a partir de projetos extensionistas voltados para esse fim. Assim, o presente estudo relata a metodologia, os resultados e desafios do projeto de extensão da Universidade Federal de Ouro Preto "Núcleo de Leitura Crítica da Mídia e Narrativas Audiovisuais". 0 texto busca promover reflexões sobre a identificação de discursos e representações preponderantes, bem como a transformação das capacidades de comunicação dos jovens envolvidos.

\section{Palavras-chave}

Crítica; Narrativas; Extensão. 


\section{Introdução}

A ampliação dos papéis exercidos pela mídia no cotidiano das pessoas é o mote central de muitos estudos sobre comunicação ao longo dos últimos anos. 0 fenômeno, considerado por muitos autores como "midiatização", revela uma ampliação da produção de conteúdos, da emissão e da circulação de mensagens. Possibilitada por aparatos tecnológicos, essa expansão, além de representar uma mudança nos processos de recepção, tendo em vista a apropriação de conteúdos, a negociação de sentidos e a ressignificação de mensagens, ocorre sob critérios bem diferentes dos vivenciados no passado.

$\mathrm{Na}$ atualidade, a midiatização pode ser percebida pela própria observação do nosso dia a dia: passamos mais tempo interagindo com as tecnologias de comunicação, visto que o acesso a muitos bens culturais como literatura, música, informações públicas, sistemas políticos e decisórios, entre outros, depende da participação na esfera midiática. Como indica Roger Silverstone, a midiatização pode ser descrita "como um processo fundamentalmente dialético, ainda que nem sempre igual, em que os meios de comunicação institucionalizados fazem parte da circulação geral de símbolos no interior da vida social”. (2010, p. 168, tradução nossa).

Esse fenômeno provocou mudanças profundas nos processos socioculturais da juventude, portanto, novos padrões direcionam as rotinas familiares, educacionais, religiosas, urbanas, entre outras, de crianças e adolescentes na contemporaneidade. Como argumenta Kellner (2001), as diversas formas da cultura da mídia "oferecem hoje sucedâneos para que os indivíduos e grupos sejam capazes de participar de comunidades imaginárias, por meio de estilos culturais e de consumo, e de produzir identidades individuais e grupais, apropriando-se de imagens dessa cultura" (p. 212). De maneira constante, a mídia oferece e se torna palco das imagens do que é "apropriado" em termos de modelos sociais, comportamentos sexuais, estilos e aparências.

Outra questão que envolve a socialização da juventude na contemporaneidade é a percepção do "eu" e do "outro" na estrutura social em rede. Os jovens, nessa nova condição comunicacional, constroem imagens sobre si e sobre a realidade, projetando significações. Para Martín-Barbero (2006), o reconhecimento dita as identidades contemporâneas: "direito de ser visto, ouvido, de se expressar, logo, de existir socialmente" (p. 70). Os discursos que estão na mídia envolvem os aspectos de visibilidade social, pertencimento e participação na vida pública. As experiências devem ser comunicáveis e comunicadas, a fim de que sejam compartilhadas, já que a cultura envolve interação com as tecnologias disponíveis. 
Leitura crítica da mídia e narrativas audiovisuais: experiência de jovens no município mineiro de Mariana

Mas segundo Orozco Gómez (2006), a sociedade reflete as tensões imbricadas na proposta globalizante contida na própria midiatização. A exuberância tecnológica e a ampliação do poder de produzir e difundir conhecimentos segue lado a lado com o crescente "despoder" social, particularmente comunicacional, que desafia as tentativas de fortalecer as cidadanias e tornar possível o desenvolvimento da democracia. Ao mesmo tempo em que estudos do campo comunicacional dizem sobre as novidades trazidas pela cultura midiatizada, estes firmam a necessidade da crítica, da democratização dos meios e do estabelecimento de alternativas capazes de fazer a disputa pela socialização e construção de identidades, sobretudo no que diz respeito à juventude em formação.

Nesse cenário é que se estabeleceu um vínculo entre mídia e educação com uma proposta que buscasse extrapolar as abordagens sobre o uso de tecnologias de comunicação em sala de aula, enquanto instrumentos metodológicos. São crescentes as iniciativas de "crítica da mídia" em espaços escolares e não-escolares, com a finalidade de aproximar dos estudantes as técnicas, as tecnologias, os princípios e fundamentos dos meios de comunicação, além de possibilitar experiências, análises críticas e transformações dos usos desses meios. Para Kellner e Share (2008), estas perspectivas representam as bases de uma educação voltada para a crítica da mídia, o que inclui mudanças pedagógicas.

A alfabetização crítica da mídia é uma resposta educacional que amplia a noção de alfabetização, incluindo diferentes formas de comunicação de massa, cultura popular e novas tecnologias. Ela também aprofunda o potencial da alfabetização para analisar criticamente relações entre a mídia e as audiências, informação e poder. Com essa análise corrente, a produção de mídia alternativa dá aos alunos o poder de criar suas próprias mensagens, que podem desafiar textos e narrativas de mídia (KELLNER, SHARE, 2008, p. 691).

Seguindo essa perspectiva, o projeto de extensão da Universidade Federal de Ouro Preto, intitulado "Núcleo de Leitura Crítica da Mídia e Narrativas Audiovisuais"1, desenvolveu, semanalmente, suas atividades no Centro de Referência da Infância e Adolescência (CRIA), situado na cidade de Mariana, Minas Gerais. 0 espaço, mantido pela Prefeitura Municipal, possui blocos de salas de aula, quadra, piscina e salas específicas para cursos e minicursos técnicos. Crianças e adolescentes de 7 a 17 anos podem realizar atividades educacionais, culturais, esportivas e de lazer dentro do CRIA. Vale ressaltar que esse era o cenário até 2015, visto que a

\footnotetext{
10 Projeto teve que ser suspenso em 2016 devido à instabilidade política da gestão municipal e também ao rompimento da barragem do Fundão, ocorrido em novembro de 2015, visto que a sede do CRIA acabou sendo utilizada como espaço de depósito de doações. É preciso ainda registrar que o referido projeto fazia parte do Programa "Sujeitos de suas histórias: leituras críticas, narrativas, afetos e identidades da comunidade de Mariana", da UFOP. A proposta é que o Projeto volte a ser realizado em 2017, quando, acredita-se, os problemas estejam resolvidos ou melhor encaminhados.
} 
inconstância política na cidade acaba comprometendo as políticas públicas em várias áreas sociais.

A proposta de crítica da mídia desenvolvida com os jovens do CRIA teve como foco as narrativas audiovisuais, já que a cultura imagética está fortemente presente no cotidiano da juventude. É possível dizer que "as crianças e adolescentes elegem o audiovisual como espaço de expressão de ideias e inscrição de suas marcas identitárias" (MAIA, RODRIGUES, 2011, p. 39). Com isso, o projeto de extensão estabeleceu um calendário de atividades de aprendizado, debates e produções junto aos participantes, que foram desenvolvidas dentro da própria sede do CRIA e no Instituto de Ciências Sociais Aplicadas da UFOP (o objetivo é também aproximar os jovens do ambiente universitário), entre outros espaços da cidade de Mariana.

\section{Metodologia}

Uma vez que as crianças e jovens estão, cada vez mais cedo, inseridas nos fluxos globais de consumo e identidade, é necessário um contexto educacional em que possam "aprender a questionar criticamente as mensagens que as cercam e usar a grande variedade de ferramentas disponíveis para expressar suas ideias e exercer plena participação na sociedade" (KELLNER, SHARE, 2008, p. 689). Sobre este aspecto, as atividades de crítica da mídia têm, por finalidade, a abertura de espaços para que os jovens externem suas inquietações e criem suas próprias representações.

O caminho metodológico proposto pelo projeto de extensão é o de levar os jovens ao encontro dos sistemas e linguagens audiovisuais; possibilitar a identificação das representações em disputa, os discursos que imperam e os que são silenciados; refletir sobre as questões dos direitos humanos no tocante à liberdade de expressão; oportunizar a experimentação técnica, avaliação de resultados e sentidos decorrentes das próprias produções. 0 objetivo é possibilitar que os jovens sejam também produtores culturais, refletindo sobre a qualidade da produção, o acesso, a propriedade e o consumo de mídia.

Vale a pena ressaltar que esse atravessamento midiático, típico da atualidade, ocupa lugar central na vida dos adolescentes, visto que as instituições tradicionais como a família e a escola, por exemplo, não conseguem agenciar os jovens de maneira consistente e estável. Não se quer dizer com isso que outras mediações, além das midiáticas, não interferem na produção e sentidos dessa parcela da população, entretanto, os liames comunicacionais é que sustentam de maneira mais intensa as interações cotidianas.

É preciso, contudo, questionar visões maniqueístas, que apresentam os meios de comunicação somente por um viés de manipulação, que direciona a vida das pessoas de forma unívoca. Por outro lado, também não podemos dizer que o 
indivíduo tem total liberdade de escolha e não sofre qualquer tipo de influência das instituições mediadoras da sociedade (MAIA, 2016, p. 140).

Essa é, portanto, a angulação adotada pelos realizadores do projeto; a de que é possível, por intermédio da análise crítica aos meios, alterar percepções já sacralizadas, ao mesmo tempo em que é possível configurar novas práticas comunicativas justamente por intermédio de uma recepção cidadã e ativa por parte dos receptores.

A partir dessa perspectiva, o projeto de extensão da UFOP esteve presente no CRIA por meio de oficinas semanais de produção de fotografias e vídeos. As crianças e adolescentes que frequentam o espaço podiam se inscrever, na secretaria do CRIA, para participar das oficinas do projeto, que contava com o trabalho de dois bolsistas e dois alunos voluntários do curso de Jornalismo da UFOP, tendo ainda a participação de monitores contratados pela prefeitura. A extensão já tem um histórico de ampla experiência dentro do CRIA, inclusive com produções na área do audiovisual, uma vez que o projeto da UFOP, nessa instituição, teve início em 2011.

As oficinas de fotografia e produção de vídeo do projeto de extensão orientam-se por alguns parâmetros para a crítica cultural da mídia, os quais podemos identificar nos relatos da pesquisa de Soares e Silva (2015) sobre as perspectivas filosóficas e históricas desse "fazer a crítica". Um primeiro ponto norteador é reconhecer as práticas midiáticas a partir de um eixo mais pedagógico, na experimentação com a linguagem e as práticas institucionalizadas da mídia. Outro ponto é contribuir para que os estudantes relacionem os recursos do sistema de produção com as representações e valores sociais que frequentemente estão nas mensagens. Nesse sentido, voltamo-nos para a perspectiva de formação de público. Importante também é que os estudantes compreendam a recepção das mensagens e as negociações de sentidos que acontecem nos processos de comunicação.

Em relação ao conhecimento sobre técnicas, tecnologias, princípios e fundamentos que norteiam as produções audiovisuais, relacionamos dez grandes campos de atuação do projeto de extensão relacionados à crítica da mídia:

1. Os debates sobre meios de comunicação, audiência e poder;

2. Os recortes da realidade: noções de enquadramento e edição de imagens;

3. A composição de imagens fotográficas e em vídeo, bem como as determinantes de iluminação;

4. Os olhares e sentidos gerados pelas imagens, bem como as possibilidades expressivas destas;

5. As entrevistas, pesquisas de opinião e conhecimento das histórias de vida na comunidade;

6. As representações sociais e as identidades veiculadas pela mídia; 
Leitura crítica da mídia e narrativas audiovisuais: experiência de jovens no município mineiro de Mariana

7. O contexto do objeto fotografado/registrado em vídeo: profundidade de campo e cenários;

8. As manipulações nas imagens e a construção de pensamentos através destas;

9. As rotinas de produção e trabalho em equipe;

10. As questões sobre habilidades, oportunidades de acesso e produção de conteúdo de mídia comunitária.

Baseando-nos em Soares e Silva (2015), os objetivos apresentados logo acima demonstram o lugar da crítica defendida neste texto, "um lugar de fala que depende do lugar de quem vê" (p. 6). Enquanto projeto de extensão universitária, enfatizamos nossa proposta de elaborar a crítica da mídia contando com o seu potencial transformador, que promova empoderamento, emancipação, reconhecimento e ruptura de sistemas e práticas midiáticas, bem como a ênfase na coletividade.

A partir dessas reflexões, afirmamos que a potência crítica não estaria apenas no próprio objeto (não é interna), mas também fora dele (no contexto e na recepção). Ou seja, não haveria um modo único de apresentação da realidade ou algo que precisa ser desvelado, mas a reconfiguração do sensível sob outros modos de percepção e significação (SOARES, SILVA, 2015, p. 6).

É nítido o protagonismo da juventude na cultura imagética e digital. A televisão já tem importante papel no acesso ao conhecimento e entretenimento desses jovens desde os seus primeiros anos de idade. Além disso, nos dias atuais, a socialização acontece no mundo digital, na ampliação das interações com as telas dos computadores e celulares. Os jovens estão imersos em um mundo de imagens e, desse modo, a linguagem audiovisual se tornou familiar e corriqueira, usada como fonte para a expressividade de muitos deles. Por isso, trabalhar com os discursos visuais em atividades de crítica da mídia nos leva a importantes análises sobre a prática do olhar, bem como sobre as interpretações e negociações de sentido dentro dessas particularidades de consumo de mídia pelos jovens.

Assim, mais importante do que a intensa proliferação visual é a relação que com ela estabelecemos e atualizamos, ou seja, o modo como se inscrevem nos e inscrevem os processos de subjetivação e criação.

Parece claro que experiência contemporânea continua a induzir modos de subjetivação/objetivação, de estar no mundo, que engendram vivências na forma de conceber e se relacionar com o real e o imaginário, na transformação quase que permanente da dinâmica tempo-espaço. Neste sentido, e partir de uma perspectiva histórico-cultural, as visualidades, assim como as tecnologias psicológicas envolvidas na produção do visível, têm nas relações sociais e na história sua processualidade evidenciada (CABRAL, WERNER, ZANELA, 2010, p. 117). 


\section{Resultados e Discussões}

Os resultados e as discussões sobre os quais direcionamos nossos olhares decorrem de oito meses de atividades do projeto de extensão "Núcleo de Leitura Crítica da Mídia e Narrativas Audiovisuais", compreendidos entre o segundo semestre de 2014 e o primeiro de 2015. Nesse período, os jovens puderam participar de oficinas semanais de fotografia e produção de vídeo, em que aprenderam a utilizar equipamentos, a elaborar entrevistas, a trabalhar com enquadramentos de imagens e iluminação, edição, entre outras atividades técnicas. A partir disso, experimentaram, construíram discursos e trabalharam como equipes de produção. Em todos os encontros com as coordenadoras e bolsistas os jovens foram estimulados ao debate, tanto sobre como a cultura de mídia está inserida em suas vidas como também de que forma eles poderiam ser agentes de transformação dessa mídia, enquanto produtores de discursos alternativos.

Os alunos desenvolveram um piloto de telejornal nas dependências do Instituto de Ciências Sociais Aplicadas - local onde funciona o curso de Jornalismo -, com quadros de entrevistas e modelos de noticiário. Produziram ensaios fotográficos e expuseram suas fotos no ICSA/UFOP durante a programação do evento Poéticas da Luz - 1aㅗ Semana de Fotografia. Eles também foram às ruas e gravaram uma enquete ("povo fala") sobre os hábitos de consumo de programas de TV. Fizeram ainda gravações dentro do próprio CRIA, com captação de imagens e entrevistas sobre as outras oficinas realizadas no local, bem como abordaram no conteúdo a proposta do Centro de Atenção à Infância e Adolescências na cidade de Mariana. Entrevistas em profundidade, com convidados da própria comunidade de Mariana, também foram realizadas pelos participantes do projeto.

Durante os debates, os alunos apontaram algumas percepções sobre o papel e os produtos da mídia hoje, como por exemplo: ausência de grupos da nossa sociedade nos programas televisivos e representação condizente, como jovens, idosos, negros, pobres e homossexuais; imagens que incitam a violência cotidianamente; ausência de representação da mulher enquanto trabalhadora e realizadora de grandes feitos sociais; falta de debate sobre as questões locais em relação a patrimônio, meio ambiente e desenvolvimento; que o jornalismo cumpra um papel de divulgar informações mais próximas da realidade e também "as coisas boas" que acontecem no dia a dia.

No entanto, a efetivação do trabalho, conforme a proposta apresentada neste estudo, ainda apresenta desafios. Um deles se refere à participação das crianças e adolescentes nas oficinas de maneira assídua, possibilitando a continuidade dos trabalhos. Muitos alunos 
participaram de um ou dois encontros, afastaram-se e depois retornaram; outros pararam de frequentar o espaço completamente. É sempre uma surpresa, para as coordenadoras e os bolsistas, quantos são os alunos das oficinas naquela semana. Percebemos ainda que muitos jovens frequentam o CRIA sem participar de qualquer atividade, apenas transitando pelo espaço, "ociosos".

Podemos considerar que precisamos de mais incentivo por parte da Prefeitura e dos professores do município, a fim de indicarem aos alunos as oficinas do projeto de extensão, bem como as demais atividades esportivas, culturais e de lazer oferecidas no CRIA. É necessário que políticas públicas nessa área sejam implementadas de maneira consistente, inclusive contando com a aproximação com as famílias diretamente envolvidas. Há toda uma infraestrutura e materiais de qualidade no Centro de Atenção à Infância e Adolescência, que podem ser mais bem aproveitados. Em relação ao audiovisual, por exemplo, o Centro conta com uma câmera filmadora digital, dois tripés, cerca de quinze câmeras fotográficas digitais amadoras e uma câmera fotográfica digital profissional. Além disso, uma sala de informática em que é possível realizar a edição de materiais. Para o projeto de extensão, essa infraestrutura possibilita o desenvolvimento das atividades junto aos jovens de maneira satisfatória atualmente.

Observamos ainda que um dos motivos da desmotivação das crianças foi o cancelamento do lanche às tardes, durante o intervalo das oficinas, como acontecia até o ano de 2014. Os alunos das oficinas, inclusive, apontaram a falta do lanche como algo a ser melhorado dentro do CRIA, durante os exercícios de gravação de entrevistas e enquetes.

Percebemos também a diminuição do número de adolescentes frequentando o CRIA, que era nosso público prioritário. No ano de 2015, mais crianças estavam no local, conforme nossas observações no dia a dia. Inclusive, adaptamos nossas oficinas para contemplar as crianças com idades entre 9 e 13 anos. Porém, percebemos que esse público é o que mais oscila entre as atividades do CRIA, deixando uma atividade e passando para outra que o interessou mais naquele momento, ou em que os colegas mais próximos estão. Sobretudo, são esses jovens os que ainda estão em aprendizado na área de informática (até mesmo dentro do CRIA), o que para nós é mais um desafio. Mínimos conhecimentos para utilizar as ferramentas de um computador são necessários para a aprendizagem da edição de vídeos e fotos, a finalização dos materiais que são produzidos pelos jovens, conforme a proposta da extensão. Este é um desafio posto para nossa proposta de desenvolvimento de mídia comunitária: efetivar o aspecto de transformação proposto pelas teorias de leitura crítica da mídia.

É válido ainda ressaltar que nossa proposta reconhece o papel ativo do receptor, que pode compreender melhor os processos comunicativos a partir de sua aproximação com as produções midiáticas e seu universo cultural, como observa o pesquisador José Luiz Braga, que 
alerta para a capacidade do usuário em relacionar o produto midiático com outros produtos, "de desenvolver relações entre características do produto em observação e questões do mundo e de sua vivência pessoal e social [...] em suma, inserir o produto em um conjunto de relações pertinentes para, assim, fazer uso dele segundo seus próprios interesses (p. 65, grifo do autor).

\section{Considerações finais}

As atividades do projeto de extensão possibilitaram o pensamento crítico em relação à mídia por parte dos jovens participantes, tanto na área do jornalismo quanto do entretenimento e das artes visuais. Em cada dia de oficina foi feito um exercício de "ampliação do olhar", de experimentação e partilha de conhecimento no que envolve a produção de fotografias e vídeos, com breves experimentações textuais. Procuramos provocar discussões sobre os conteúdos midiáticos consumidos; como estes fazem parte da vida dos jovens e como estão diretamente ligados às concepções sobre realidade e identidade, a partir do que a mídia potencializa em termos de discursos e processos sociais.

Diante disso, percebemos que devemos conquistar a adesão de mais jovens ao projeto, dados os desafios apontados. Já visualizamos a necessidade de fazer um trabalho junto às escolas próximas à sede do CRIA, a fim de que os professores ajudem a motivá-los e incentivá-los a participar das oficinas do "Núcleo de Leitura Crítica da Mídia e Narrativas Audiovisuais". Um incentivo para futuras iniciativas foi o ingresso, em 2016, no curso de Jornalismo da UFOP, de uma das alunas participantes do Projeto de extensão.

Vale ainda registrar que as instituições de ensino, em especial as Universidades, precisam estar atentas às novas percepções e apropriações dos jovens no campo midiático. Os estudantes não podem ser meros depositários do conhecimento; é preciso pensar uma educação voltada para a autonomia, em oposição à "concepção bancária da educação", tão questionada pelo educador Paulo Freire (1983). Esses novos fluxos comunicacionais trazem a potência que necessita ser acionada para que a comunicação seja encarada como um direito social da juventude e da população brasileira.

\section{Referências}

BRAGA, José Luiz. 0 sistema de resposta social; Das interações sociais aos processos críticos. In: BRAGA, José Luiz. A sociedade enfrenta sua mídia: dispositivos sociais de crítica midiática. São Paulo: Paulus, 2006, p. 21-67.

CABRAL, Marcelo Grimm; WERNER, Francyne; ZANELLA, Andréa Vieira. A sociedade da imagem e a imagem da sociedade: discursos visuais produzidos por jovens em contexto escolar. Revista 
Leitura crítica da mídia e narrativas audiovisuais: experiência de jovens no município mineiro de Mariana

Eletrónica de Investigación y Docencia, n. 4, 2010, p. 113-130. Disponível em: <http://www.ujaen.es/revista/reid/revista/n4/REID4art6.pdf>. Acesso em: ago. 2015.

FREIRE, Paulo. Pedagogia do oprimido. Rio de Janeiro: Paz e Terra, 1983.

GÓMEZ, Guillermo Orozco. Comunicação social e mudança tecnológica: um cenário de múltiplos desornamentos. In: MORAES, Dênis (org). Sociedade midiatizada. Rio de Janeiro: Mauad, 2006.

KELLNER, Douglas. A cultura da mídia. Estudos culturais: identidade e política entre o moderno e o pós-moderno. São Paulo: EDUSC, 2001.

KELLNER, Douglas. SHARE, Jeff. Educação para a leitura crítica da mídia, democracia radical e a reconstrução da educação. Educação e Sociedade, v. 29, n.104, p. 687-715, Campinas-SP: E. Cortez, CEDES, 2008.

MAIA, Marta R. Juventude e conexões midiáticas. In: Cláudia Braga de Andrade; Margareth Diniz; Carla Mercês da Rocha Jatobá Ferreira. (Org.). Juventudes e o Mal-Estar na Contemporaneidade. $1^{\mathfrak{a}}{ }^{\mathrm{e}} \mathrm{d} ., \mathrm{J}$ Jundiaí: Paco Editorial, 2016, p. 129-144.

MAIA, Marta; RODRIGUES, Hila; Juventude, imagem e som: recriando narrativas audiovisuais. In: Rocha, Adriano Medeiros da et al. Audiovisual e Juventude. Ouro Preto: UFOP, 2011.

MARTÍN-BARBERO, Jésus. Tecnicidades, identidades, alteridades: mudanças e opacidade da comunicação no novo século. In: MORAES, Dênis (org). Sociedade midiatizada. Rio de Janeiro: Mauad, 2006.

SILVERSTONE, Roger. La retórica del mal. In SILVERSTONE, Roger. La moral de los medios de comunicación: Sobre el nacimiento de la polis de los medios. Buenos Aires: Amorrortu, 2010, p. 90-126.

SOARES, Rosana de Lima; SILVA, Gislene da. Lugares da crítica na cultura midiática. Anais do XXII Encontro Anual da Compós (Associação Nacional dos Programas de Pós-Graduação), 2015. Disponível em: http://compos.org.br/biblioteca/compos-2015-af0869a7-a6fe-4c92-b62317d811a5d358_2822.pdf. Acesso em: 20 ago. 2015. 
Critical media reading and audiovisual narratives: experiences of young people in Mariana city

\begin{abstract}
The issues surrounding the relationship between media and education pervade the contemporary context, marked by the strong presence of communication technologies in sociocultural processes. Therefore, there is the need to promote critical media readings. In this interactive process, the questions can tighten the media practices from extension projects for this purpose. The present study reports the methodology, results and challenges of the extension project of the Federal University of Ouro Preto "Critical Media Reading Core and Audiovisual Narratives". The text seeks to promote reflections on the identification of speeches and predominant representations, as well as the transformation of communication skills of young people involved.
\end{abstract}

\section{Keywords}

Critical, Narratives, Extension
Lectura crítica de los medios y narrativas audiovisuales: experiencia de la juventud en la ciudad minera de Mariana

\section{Resumen}

Los problemas que rodean la relación entre los medios y la educación impregnan el contexto actual, marcado por la fuerte presencia de las tecnologías de la comunicación en los procesos socioculturales. Por lo tanto, existe la necesidad de promover las lecturas críticas de los medios. En este proceso interactivo, desde un proyecto de extensión, se puede plantear interrogantes sobre prácticas de los medios. El presente estudio presenta los resultados y la metodología, los retos del proyecto de extensión de la Universidad Federal de Ouro Preto "Núcleo de lectura crítica de los medios y narrativas audiovisuales". El texto busca promover la reflexión sobre la identificación de los discursos y representaciones predominantes, así como la transformación de las habilidades de comunicación de los jóvenes que participan.

\section{Palabras clave}

Crítica, Narrativas, Extensión

Original submetido em: 8 ago. 2016

Aceito para publicação em: 7 out. 2016

Sobre as autoras:

Marta Regina Maia

Professora Adjunta IV do Programa de Pós-Graduação em Comunicação e do curso de Jornalismo da Universidade Federal de Ouro Preto (Minas Gerais Brasil). Doutora em Ciências da Comunicação pela Escola de Comunicações e Artes da Universidade de São Paulo, com pós-doutoramento no Programa de Pós-Graduação em Comunicação Social da Universidade Federal de Minas Gerais (Brasil). Líder do Grupo de Pesquisa Jornalismo, Narrativas e Práticas Comunicacionais.

\section{Monique Ferreira Campus}

Técnica de Laboratório da UFOP nas áreas de Fotografia e Planejamento Visual. Mestre em Comunicação e Identidades pela Universidade Federal de Juiz de Fora (Minas Gerais - Brasil) e jornalista graduada na mesma instituição. 